Chronic Obstructive Pulmonary Diseases: Journal of the COPD Foundation

\author{
Original Research
}

\title{
Hiatal Hernia on Chest High-Resolution Computed Tomography and Exacerbation Rates in COPD Individuals
}

Cynthia Kim, $\mathrm{MD}^{1^{*}}$ Wei Ouyang, $\mathrm{MD}^{2^{*}}$ Chandra Dass, $\mathrm{MD}^{2}$ Huaqing Zhao, $\mathrm{PhD}^{3}$ Gerard J. Criner, $\mathrm{MD}^{1}$ and the COPDGene Investigators

\section{Abstract}

Background: Gastroesophageal reflux disease (GERD) is associated with frequent chronic obstructive pulmonary disease (COPD) exacerbations. Hiatal hernia (HH) contributes to GERD pathogenesis and is identifiable on chest high-resolution computed tomography (HRCT). We hypothesize that the presence of an $\mathrm{HH}$ on $\mathrm{HRCT}$ identifies those at increased risk for acute exacerbation of COPD.

Methods: We retrospectively reviewed a prospectively enrolled cohort of smokers with and without airflow obstruction. HHs were identified visually on inspiratory HRCT. Individuals' demographic and clinical information was compared with secondary analysis performed using a propensity score generated matched cohort.

Results: There were 523 COPD individuals and 607 unobstructed smokers. COPD individuals had more HHs than unobstructed smokers, $(11.6 \%$ versus $6.1 \%, p<0.001)$. COPD individuals with hernias were older, female, overweight and GERD positive as compared to those without hernia. There was no difference in self-reported exacerbation rates or hospitalizations per year, but similar severity of obstruction, smoking rates and long-term oxygen use. Analysis with the matched cohort revealed no significant difference in exacerbation rates.

Conclusions: Presence of HHs on inspiratory HRCT scan did not predict worse symptoms or exacerbation rate in COPD individuals. Those with HHs were older, more obese, and predominantly female compared to those without HHs.

\footnotetext{
Abbreviations: gastroesophageal reflux disease, GERD; chronic obstructive pulmonary disease, COPD; hiatal hernia, HH; high-resolution computed tomography, HRCT; COPD Epidemiology study, COPDGene; forced expiratory volume in 1 second, FEV $\mathbf{1}_{\mathbf{1}}$; forced vital capacity, FVC; modified Medical Research Council dyspnea scale, mMMC; body mass index, BMI; long-acting muscarinic antagonist, LAMA; longacting beta-agonist, LABA; inhaled corticosteroids, ICS; short-acting beta-agonist, SABA; short-acting muscarinic antagonist, SAMA

Funding Support: National Institutes of Health funded COPDGene grants R01 HL089856 and R01 HL089897

Date of Acceptance: January 9, 2016

Citation: Kim C, Ouyang W, Dass C, Zhao H, Criner GJ, COPDGene Investigators. Hiatal hernia on chest high-resolution computed tomography and exacerbation rates in COPD individuals. Chronic Obstr Pulm Dis (Miami). 2016; 3(2):570-579. doi: http://dx.doi. org/10.15326/jcopdf.3.2.2015.0158
}

1 Department of Pulmonary and Critical Care Medicine, Temple University Hospital, Philadelphia, Pennsylvania

2 Department of Radiology, Temple University Hospital, Philadelphia, Pennsylvania

3 Temple Clinical Research Center, Temple University School of Medicine, Philadelphia, Pennsylvania

* Co-first Authors

\section{Address correspondence to:}

Cynthia Kim, MD

Temple Lung Center

7th Floor Parkinson Pavilion

3401 North Broad Street

Philadelphia, PA 19140

Phone: 267-858-2735

Email: cynthia.kim@tuhs.temple.edu

\section{Keywords:}

hiatal hernia; COPD exacerbation; gastroesophageal reflux disease 


\section{Background}

Patients with advanced chronic obstructive pulmonary disease (COPD) have a higher incidence of gastroesophageal reflux disease (GERD) that can often be asymptomatic and found only with esophageal $\mathrm{pH}$ monitoring. ${ }^{1-5}$ Patients with clinically significant GERD symptoms seem to have more COPD exacerbations and hospitalizations than individuals without these symptoms. ${ }^{6-8}$ In addition, poor control of GERD symptoms negatively impacts the quality of life in COPD. ${ }^{9}$ Given the significant morbidity and health care burden associated with acute exacerbations in $\mathrm{COPD},{ }^{10-12}$ finding a non-invasive marker for gastroesophageal disease could help identify patients prone to acute exacerbations.

The presence of a hiatal hernia $(\mathrm{HH})$ has been identified as a risk factor for developing GERD symptoms through a complex range of mechanisms including anatomic disruption of the lower esophageal sphincter and delayed esophageal-emptying. ${ }^{13-15}$ $\mathrm{HHs}$ are easily identified on non-contrast computed tomography (CT) of the chest as a proximal displacement of the esophagogastric junction through the esophageal hiatus of the diaphragm into the mediastinum. ${ }^{16,17}$ Noth demonstrated the efficacy of using CT thorax images for identification of $\mathrm{HH}$ in patients with pulmonary fibrosis. ${ }^{18}$ We aim to investigate whether the presence of $\mathrm{HH}$ s on routine chest $\mathrm{CT}$ performed on COPD individuals can serve as a convenient marker for identification of individuals prone to frequent or severe exacerbations.

\section{Methods}

We performed a retrospective data analysis of prospectively collected data from the COPD Genetic Epidemiology (COPDGene) database, a multicenter prospective observational study involving 21 academic centers in the United State and 10,300 individuals. Both current and former cigarette smokers with and without COPD, self-identified as African-American and non-Hispanic white, were recruited. Individuals were 45 to 80 years of age with at least 10 pack years of smoking history. Exclusion criteria were pregnancy, history of other lung disease except asthma, prior lobectomy or lung volume reduction surgery, active cancer undergoing treatment, or known or suspected lung cancer.
Approval was obtained from the governing body of the COPDGene database as well as the institutional review board of Temple University (protocol \#22381). For our study, we used the 1190 individuals recruited from Temple University Hospital with available images for review. Those with incomplete data such as missing CT scans or database information were excluded leaving 1130 individuals who were then categorized by spirometry into those with COPD (forced expiratory volume in 1 second [FEV 1 ] to forced vital capacity [FVC] ratio $<0.7$ ) or smokers without obstruction (Figure 1 ).

Upon enrollment, individuals were surveyed regarding a number of clinical conditions. Those reporting a history of heartburn, acid reflux, or stomach ulcers were considered positive for GERD. Comorbidities such as angina, congestive heart failure, coronary artery disease, high blood pressure, and high cholesterol, as well as the presence and timing of symptoms such as cough and phlegm production were identified using a modified American Thoracic Society Respiratory Epidemiology questionnaire. $^{19}$ Exacerbations were defined as any episode 1 year prior to enrollment during which the individual experienced shortness of breath or change in sputum production requiring an increase in medication. Frequent exacerbations were defined as having 2 or more exacerbations per year. Severe exacerbations were defined as those requiring hospitalization. Spirometry data and CT scans were performed prospectively at the time of enrollment. Dyspnea was assessed using the modified Medical Research Council (mMRC) dyspnea scale.

CT scans were acquired in spiral mode using multi-detector scanners (Siemens, Sensation-16 and Sensation-64, Malvern, PA, USA). Images were obtained with breath held on deep inspiration and at the end of normal expiration. The exposure factors were effective $\mathrm{mAs}$ of 200 for inspiration, $50 \mathrm{mAs}$ for expiration, and $120 \mathrm{kVp}$ for both. Tube rotation time of 0.5 seconds and pitch of 1.1 were used. Images were reconstructed in the axial plane at $0.75 \mathrm{~mm}$ slice thickness, with $0.5 \mathrm{~mm}$ interval, using both soft tissue (B31f) and high spatial frequency (B46f) algorithms. Monthly scanning, using a custom COPDGene phantom, provided monitored stability of CT measurements for each scanner. Onemillimeter thick coronal and sagittal images were reconstructed.

The presence of an $\mathrm{HH}$ was determined by visual examination of the inspiratory CT. Since mucosal detail is poorly visualized, extrinsic morphology was used to 
identify the level of the esophagogastric junction with respect to the esophageal hiatus of the diaphragm. The study was negative for HHs if the angle of His was identified below the diaphragm (Figure 2A). We used $\mathrm{CT}$ features classic for herniation of gastric tissue to identify herniation above the esophageal hiatus: abrupt concentric contour enlargement, rugal folds, and focal irregular lobulation. The hernias were then categorized as definite, probable, and possible based on length. First, an oblique line was drawn through the anterior and posterior aspects of the esophageal hiatus on a sagittal image centered on the hiatus. Next, the height

\section{Figure 1. Individual Selection Flow Diagram}

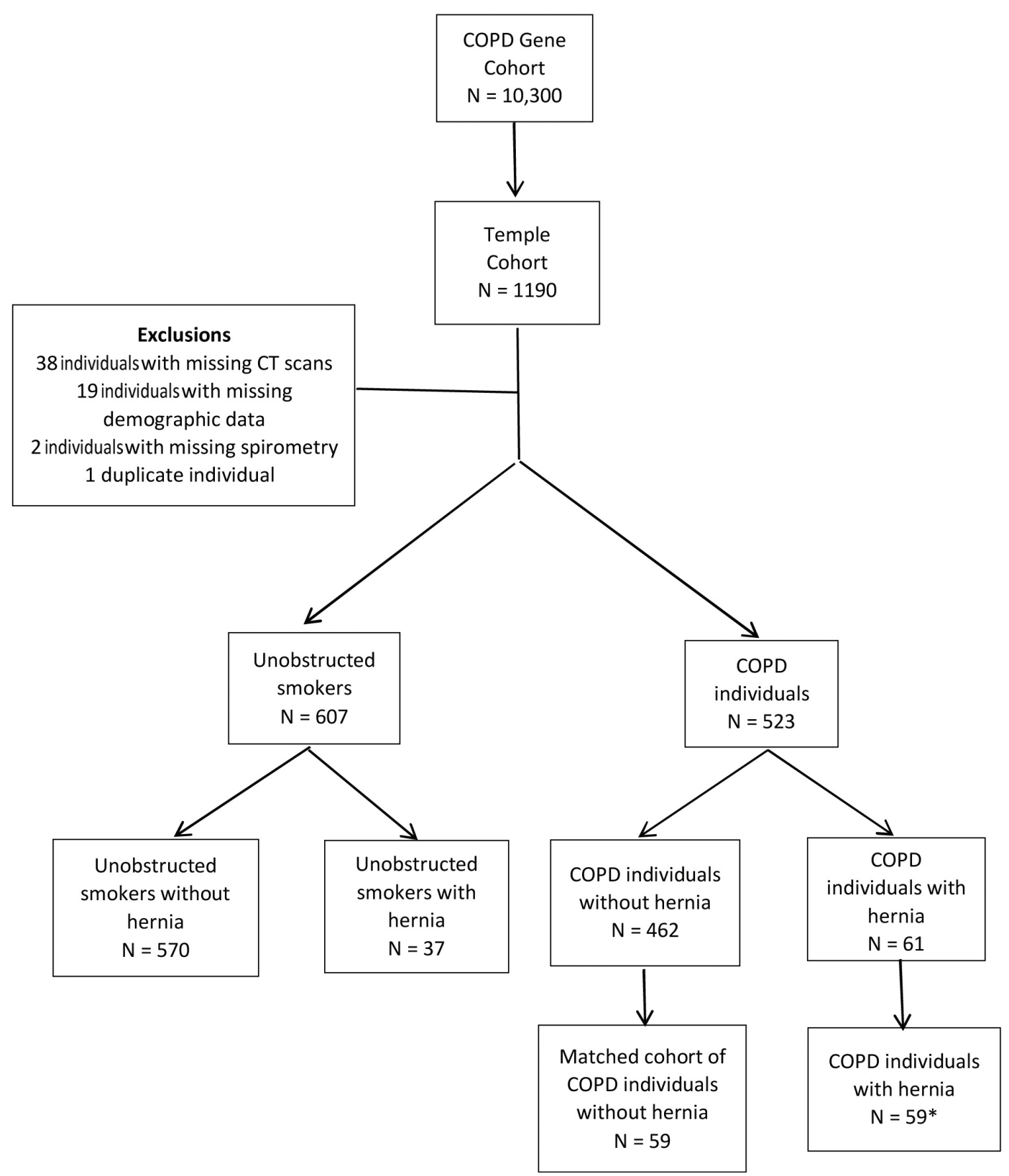

Individuals from the COPDGene cohort recruited from Temple University Hospital were divided into those with COPD and unobstructed smokers. Both of these groups were then sorted by the presence of hiatal hernia and compared. To control for confounders, a smaller propensity score matched cohort was identified and used for comparison. "Two patients were unable to be matched with propensity scoring and were excluded from the matched cohort. was measured by drawing a perpendicular line up to the superior margin of the hernia (Figure 2B). Definite hernias were those longer than $2 \mathrm{~cm}$, probable ones were those between 1 and $2 \mathrm{~cm}$, and possible ones were those between 0 and $1 \mathrm{~cm}$. Since by radiographic convention, an $\mathrm{HH}$ is defined as displacement of the esophagogastric junction by more than $1 \mathrm{~cm}$ above the hiatus, ${ }^{20}$ we considered possible hernias negative during data analysis. The maximum transverse diameters of the hernias were obtained on axial images.

Participant data was analyzed by JMP Pro software version 10.0.2d1. Groups with and without hernia (both COPD individuals and unobstructed smokers) were compared with t-test for normally distributed variables and by Wilcoxon rank sum test for all other variables. Unobstructed smokers without hernia were compared to those with hernia to examine if the presence of hiatal hernia alone caused respiratory symptoms in the absence of COPD. Further analysis was done to look at the effect of 
confounding variables on COPD individuals with an $\mathrm{HH}$ compared to those without an $\mathrm{HH}$ with respect to exacerbation frequency. Due to the size and distribution disparities between the COPD individuals with and without HHs, propensity scoring was used to create a matched cohort for comparison. The score was calculated using gender, race, age, body mass index (BMI), the presence of GERD symptoms and hyperlipidemia and then used to identify a matched cohort of COPD individuals without HHs comparable

\section{Figure 2A. Representative Coronal Oblique CT Thorax Images}

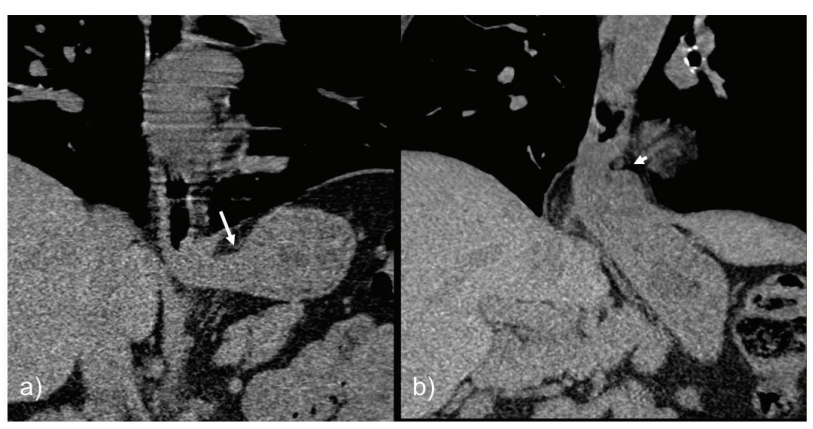

Representative coronal oblique CT thorax images that represent a) a negative study with the angle of His (arrow) below the diaphragm and b) a positive study with gastric tissue above the diaphragm as evidenced by contour enlargement (arrowhead). to the test population. Two COPD individuals with $\mathrm{HHs}$ did not have an identifiable propensity score matched control and were eliminated from that portion of the analysis (Figure 1). COPD individuals with $\mathrm{HH}$ sere then compared to the smaller propensity score-matched cohort to determine if any of the previously mentioned variables had an effect on exacerbation rates. Both sets of analyses are reported here. Data were considered significant with a $p$ value $<0.05$ and is presented in the form of either a percentage with the associated $\mathrm{N}$ value or as mean with standard deviation.

\section{Results}

Of the 1130 individuals investigated, 98 (8.6\%) probable or definite $\mathrm{HH}$ s were identified. Of these, 54 $(4.8 \%)$ were definite $\mathrm{HHs}$ and 45 (3.9\%) were probable hernias. The maximum transverse diameter of the hernias ranged from $2.1 \mathrm{~cm}$ to $10.1 \mathrm{~cm}$ as measured on axial images. There was a significantly higher incidence of $\mathrm{HHs}$ among individuals with COPD as compared to unobstructed smokers $(11.6 \%$ [61/523] versus $6.1 \%$ [37/607], $p<0.001)$. A total of $6.5 \%(\mathrm{~N}=34)$ of these individuals had a definite hernia.

\section{Description and Exacerbation Rates of COPD Individuals}

Of 1130 individuals, 523 had COPD as defined by spirometry with an $\mathrm{FEV}_{1} / \mathrm{FVC}<0.7$. The $61 \mathrm{COPD}$

\section{Figure 2B. Representative Sagittal CT Thorax Images Centered on the Esophageal Hiatus}

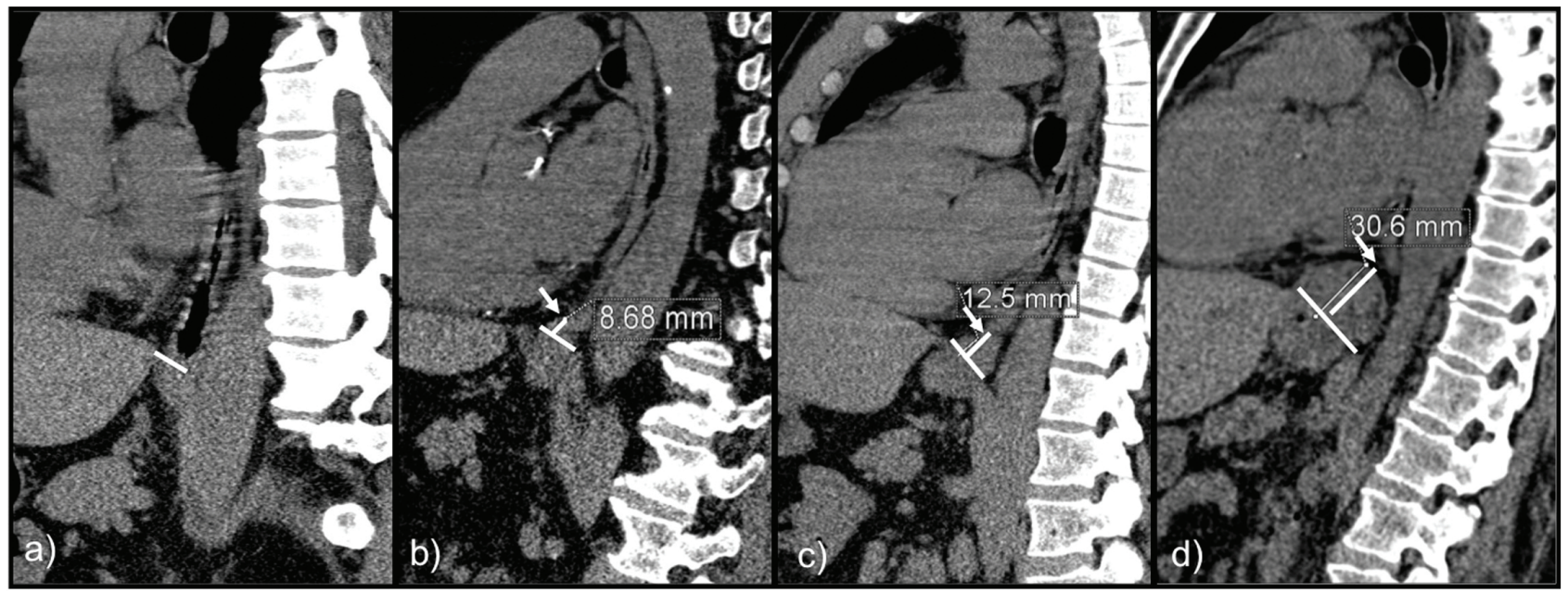

Representative sagittal CT thorax images centered on the esophageal hiatus showing a) a negative study with a line drawn through the level of the esophageal hiatus, b) a possible study as measured by a line drawn from the hiatus to the contour change (arrow) indicating the level of the esophagogastric junction measuring $0-1 \mathrm{~cm}$ in length, c) a probable hernia with a length of $1-2 \mathrm{~cm}$, d) and a definite hernia with a length greater than $2 \mathrm{~cm}$. 
individuals with hernias (11.6\%) were more likely to be female, white, older and have a higher BMI compared to COPD individuals without hernias (Table 1). COPD individuals with a hernia as compared with COPD individuals without a hernia had a similar rate of pack year cigarette use, level of obstruction on spirometry and the prevalence of long-term supplemental oxygen use. The majority of COPD individuals with and without HHs had Global initiative for chronic Obstructive Lung Disease $^{21}$ (GOLD) Stage II or III disease ( $p=0.68$ ).

COPD individuals with an $\mathrm{HH}$ had significantly more GERD but similar rates of gastric ulcers. The incidence of comorbidities such as congestive heart failure, coronary artery disease, diabetes, and hypertension were equal between COPD individuals with and without HHs. Hyperlipidemia, however, was significantly increased in COPD individuals with an HH (Table 1). There were similar rates of cough, cough productive with phlegm and perception of dyspnea as defined by the mMRC.

There was no significant difference in self-reported exacerbation rates $(0.67 \pm 1.1$ versus $0.83 \pm 1.29$, $p=0.37$ ), or percentage of individuals experiencing severe exacerbations in the past year (23\% versus $29.4 \%, p=0.29$ ). The percentage of individuals with frequent exacerbations was slightly lower in the group with hernia as compared with COPD individuals without $\mathrm{HH}$, but was not significantly different $(11.5 \%$ versus $17.5 \%, p=0.29)$.

Rates of rescue medications or controller medications use between COPD individuals with and without $\mathrm{HHs}$ were similar. COPD individuals with a hernia had an increased rate of long-acting muscarinic antagonists (LAMAs) use (59\% versus $49.4 \%, p=0.16)$ but the difference was not significant (Table 2). Long-term follow up data was available for 424 of the 523 individuals and showed no significant difference in

\section{Table 1. Demographic Data and Incidence of Comorbidities for Individuals}

\begin{tabular}{|c|c|c|c|c|}
\hline & \multicolumn{2}{|c|}{ COPD Individuals } & \multicolumn{2}{|c|}{ Unobstructed Smokers } \\
\hline & $\begin{array}{l}\text { With Hernia } \\
\qquad(N=61)\end{array}$ & $\begin{array}{l}\text { Without Hernia } \\
\qquad(\mathrm{N}=462)\end{array}$ & $\begin{array}{l}\text { With Hernia } \\
\qquad(\mathrm{N}=37)\end{array}$ & $\begin{array}{l}\text { Without Hernia } \\
\qquad(\mathrm{N}=570)\end{array}$ \\
\hline \multicolumn{5}{|l|}{$\%(\mathbf{N})$} \\
\hline Male & $41.9 \%(26)^{a}$ & $56.1 \%(259)^{a}$ & $45.9 \%(17)$ & $54.1 \%(308)$ \\
\hline Female & $57.4 \%(35)$ & $43.9 \%(203)$ & $54.1 \%(20)$ & $45.9 \%(262)$ \\
\hline Oxygen Therapy & $19.7 \%(12)$ & $23.2 \%(107)$ & $2.7 \%(1)$ & $0.7 \%(4)$ \\
\hline White & $63.9 \%(39)^{2}$ & $45.7 \%(211)^{a}$ & $35.1 \%(13)^{a}$ & $18.8 \%(107)^{a}$ \\
\hline \multicolumn{5}{|l|}{ (mean \pm SD) } \\
\hline Age (yrs) & $64 \pm 8.9^{a}$ & $61 \pm 8.3^{a}$ & $58.9 \pm 8.5^{a}$ & $53.1 \pm 6.8^{\mathrm{a}}$ \\
\hline BMI $\left(\mathrm{kg} / \mathrm{m}^{2}\right)$ & $30.1 \pm 5.8^{a}$ & $27.9 \pm 6.3^{a}$ & $30.1 \pm 6.02$ & $29.7 \pm 6.4$ \\
\hline Smoking History (pack years) & $48.9 \pm 23.8$ & $52.3 \pm 29.2$ & $43.1 \pm 24.9$ & $40.6 \pm 21.6$ \\
\hline FEV $_{1}(\%)$ & $50.7 \pm 20$ & $49.2 \pm 21.6$ & $84.9 \pm 18.8$ & $88.2 \pm 16.8$ \\
\hline FVC (\%) & $75.4 \pm 18.7$ & $73.8 \pm 20.2$ & $75.2 \pm 17.8$ & $88.8 \pm 16.1$ \\
\hline FEV $_{1} /$ FVC & $0.5 \pm 0.11$ & $0.49 \pm 0.13$ & $0.78 \pm 0.5$ & $0.79 \pm 0.5$ \\
\hline \multicolumn{5}{|l|}{ Comorbidities - \% (N) } \\
\hline GERD & $37.7 \%(23)^{a}$ & $17.1 \%(79)^{\mathrm{a}}$ & $32.4 \%(12)^{a}$ & $13.2 \%(75)^{a}$ \\
\hline Ulcers & $4.8 \%(3)$ & $7.4 \%(34)$ & $0 \%(0)$ & $5.1(29)$ \\
\hline Congestive Heart Failure & $3.3 \%(2)$ & $4.6 \%(21)$ & $2.7 \%(1)$ & $2.3 \%(13)$ \\
\hline Coronary Artery Disease & $9.8 \%(6)$ & $5.8 \%(27)$ & $0 \%(0)$ & $3 \%(17)$ \\
\hline Diabetes Mellitus & $11.5 \%(7)$ & $14.2 \%(66)$ & $10.8 \%(4)$ & $14.8 \%$ \\
\hline Hypertension & $50.8 \%(31)$ & $47.6 \%(220)$ & $45.9 \%(17)$ & $36.3(207)$ \\
\hline Hyperlipidemia & $49.2 \%(30)^{a}$ & $33.8 \%(156)^{a}$ & $32.4 \%(12)$ & $23.3 \%(133)$ \\
\hline
\end{tabular}

Data is presented as a percentage \% with the number of individuals in parentheses (N) or as a mean with standard deviation (SD).

$a=$ significant $p$ values $<0.05$

$\mathrm{BMI}=$ Body Mass Index; $\mathrm{FEV}_{1}=$ forced expiratory volume in 1 second; $\mathrm{FVC}=$ forced expiratory volume;

GERD = gastroesophageal reflux disease 


\section{Table 2. Outcomes: Reported Symptoms, Exacerbations and Medication Use}

\begin{tabular}{|c|c|c|c|c|}
\hline & \multicolumn{2}{|c|}{ COPD Individuals } & \multicolumn{2}{|c|}{ Unobstructed Smokers } \\
\hline & $\begin{array}{l}\text { With Hernia } \\
\qquad(\mathrm{N}=61)\end{array}$ & $\begin{array}{l}\text { Without Hernia } \\
\qquad(\mathrm{N}=462)\end{array}$ & $\begin{array}{l}\text { With Hernia } \\
\qquad(\mathrm{N}=37)\end{array}$ & $\begin{array}{l}\text { Without Hernia } \\
\qquad(\mathrm{N}=570)\end{array}$ \\
\hline \multicolumn{5}{|l|}{ Symptoms - \% (N) } \\
\hline Cough & $42.6 \%(26)$ & $42.6 \%(197)$ & $37.8 \%(14)$ & $41.1 \%(234)$ \\
\hline Phlegm & $47.5 \%(29)$ & $53.1 \%(245)$ & $29.7 \%(11)$ & $34.4 \%(196)$ \\
\hline Wheeze & $68.9 \%(42 \%)$ & $70.6 \%(326)$ & $56.7 \%(21)^{b}$ & $41.6 \%(237)^{b}$ \\
\hline mMRC & $2.5 \pm 1.3$ & $2.4 \pm 1.5$ & $1.59 \pm 1.7$ & $1.23 \pm 1.5$ \\
\hline Angina & $3.3 \%(2)$ & $5 \%(23)$ & $10.8 \%(4)^{a}$ & $3.5 \%(20)^{a}$ \\
\hline \multicolumn{5}{|l|}{ Reported Exacerbations } \\
\hline Exacerbations (mean \pm SD) & $0.67 \pm 1.1$ & $0.83 \pm 1.29$ & & \\
\hline Severe Exacerbations & $23 \%(14)$ & $29.4 \%(136)$ & & \\
\hline Frequent Exacerbators & $11.5 \%(7)$ & $17.5 \%(81)$ & & \\
\hline \multicolumn{5}{|l|}{ Medication Use - \%(N) } \\
\hline SABA & $60.6 \%(37)$ & $60.5 \%(279)$ & $21.6 \%(8)$ & $15.5 \%(88)$ \\
\hline SAMA & $4.9 \%(3)$ & $9.6 \%(44)$ & $5.41 \%(2)$ & $1.93 \%(11)$ \\
\hline SABA/SAMA & $27.4 \%(17)$ & $26.9 \%(124)$ & $13.9 \%(5)^{b}$ & $6.14 \%(35)^{b}$ \\
\hline Nebulizer & $45.2 \%(24)$ & $48.1 \%(223)$ & $24.3 \%(9)^{a}$ & $12.5 \%(71)^{a}$ \\
\hline Oral Steroids & $11.3 \%(7)$ & $9.78 \%(45)$ & $5.41 \%(2)$ & $1.93 \%(11)$ \\
\hline LABA & $11.5 \%(7)$ & $10.7 \%(49)$ & $2.7 \%(1)$ & $1.2 \%(7)$ \\
\hline LABA/ICS & $51.6 \%(32)$ & $47.6 \%(219)$ & $18.9 \%(7)^{a}$ & $7.37 \%(42)^{a}$ \\
\hline LAMA & $59 \%(36)$ & $49.4 \%(227)$ & $10.9 \%(4)$ & $7.2 \%(41)$ \\
\hline ICS & $8.2 \%(5)$ & $14.3 \%(66)$ & $0 \%(0)$ & $2.9 \%(17)$ \\
\hline
\end{tabular}

mMRC is the modified Medical Research Council scale for dyspnea. Exacerbations are self-reported increases in symptoms requiring an increase in therapy where as Severe Exacerbations are those requiring hospitalization. Frequent Exacerbators are defined as those with 2 or more exacerbations in 1 year and the data is reported as a percentage of the total population.

$\mathrm{SABA}=$ short-acting beta agonist; SAMA = short-acting muscarinic antagonist; LABA = long-acting beta agonist; ICS = inhaled corticosteroid; LAMA = long-acting muscarinic antagonist

$a=$ significant $p$ values $<0.05$

b $=p$-value -0.07

exacerbations per year $(0.8 \pm 1.3$ versus $0.7 \pm 1.3$, $p=0.47$ ). There was also no difference in mortality between the 2 groups ( $8.3 \%$ versus $6.7 \%, p=0.67$ ). COPD individuals with hernias were matched to a propensity score matched cohort. The score was able to create a matched cohort of COPD individuals without $\mathrm{HHs}$ with similar gender, race, and incidence of acid reflux, hyperlipidemia, age, BMI and level of obstruction to that of the $\mathrm{HH}$ group to control for the effect of these variables. Repeat analysis between these 2 revealed similar mean exacerbation rates $(0.68 \pm 1.12$ versus $0.88 \pm 1.29, p=0.36$ ) and percentage of individuals with severe exacerbations $(23.7 \%$ versus $28.8 \%, p=0.53)$. (Table 3).

\section{Description and Exacerbations Rates for Unobstructed Smoking Individuals}

Statistically significant clinical differences were found within the 607 smoking individuals without obstruction $\left(\mathrm{FEV}_{1} / \mathrm{FVC}>0.7\right)$. As stated above, there were significantly fewer unobstructed smokers with hernias than COPD individuals with hernias. However, the 2 hernia positive groups shared characteristics of older age, white predominance and increased incidence of GERD. Unobstructed smokers with $\mathrm{HH}$ s were similar to unobstructed smokers without HHs in terms of gender, BMI, length of smoking history, and level of obstruction (Table 1).

Unobstructed smokers with hernias were more likely to complain of angina but had similar incidences of coronary artery disease, congestive heart failure, diabetes, hypertension, and hyperlipidemia. Frequency of cough, rates of phlegm production and $\mathrm{mMRC}$ were similar between the 2 groups. Increased wheeze in the hernia group trended toward significance. Those with hernia were significantly more likely to have a nebulizer 


\section{Table 3. Data Comparing COPD Individuals With Hiatal Hernia Against a Matched Cohort of COPD Individuals Without Hiatal Hernia}

\begin{tabular}{|c|c|c|c|}
\hline & $\begin{array}{l}\text { With Hernia } \\
\quad(\mathrm{N}=59)\end{array}$ & $\begin{array}{l}\text { Without Hernia } \\
\qquad(N=59)\end{array}$ & $P$ value \\
\hline$\%(\mathbf{N})$ & $57.6 \%(34)$ & $50.9 \%(30)$ & 0.36 \\
\hline Male & $62.7 \%(37)$ & $59.3 \%(35)$ & 0.71 \\
\hline White & $35.6 \%(21)$ & $37.3 \%(22)$ & 0.85 \\
\hline Presence of GERD & $47.5 \%(28)$ & $57.6 \%(34)$ & 0.27 \\
\hline Hyperlipidemia & $57.6 \%(34)$ & $50.9 \%(30)$ & 0.36 \\
\hline \multicolumn{4}{|l|}{ (mean \pm SD) } \\
\hline Age (years) & $63.8 \pm 8.9$ & $63.5 \pm 8.3$ & 0.89 \\
\hline BMI (kg/m²) & $29.9 \pm 5.7$ & $30.1 \pm 7.1$ & 0.85 \\
\hline FEV $_{1}(\%)$ & $50.7 \pm 19.6$ & $54.1 \pm 19.9$ & 0.36 \\
\hline \multicolumn{4}{|c|}{ Exacerbation Frequency } \\
\hline $\begin{array}{l}\text { Exacerbations } \\
\text { (mean } \pm \text { SD) }\end{array}$ & $0.68 \pm 1.12$ & $0.88 \pm 1.29$ & 0.36 \\
\hline$\%(\mathbf{N})$ & $23.7 \%$ (14) & $28.8 \%(17)$ & 0.53 \\
\hline Severe Exacerbations & $2 B 17.98 / 1(7)$ & $28.8 \%(12)$ & $0.8 B$ \\
\hline Frequent Exacerbators & $11.9 \%(7)$ & $20.3 \%(12)$ & 0.21 \\
\hline
\end{tabular}

The matched cohort was generated using propensity score matching to control for gender, BMI, length of smoking history, and degree of obstruction on spirometry.

$P$-values are provided for the variables used to demonstrate the efficacy of propensity score matching.

Two COPD individuals with HHs were excluded from this analysis since a propensity score match was not found.

at home and use a long-acting beta-agonist ( LABA)/ inhaled corticosteroids (ICS) combination. There was a trend towards more short-acting beta-agonists (SABAs)/short-acting muscarinic antagonists (SAMAs) use in the group with $\mathrm{HHs}$ that did not reach statistical significance (Table 2).

\section{Discussion}

In our study, we found that the presence of $\mathrm{HHs}$ on CT imaging does correlate with an older, more obese population with a higher incidence of GERD and that HHs occur significantly more frequently in individuals with COPD as compared with unobstructed smokers. Patients with $\mathrm{HHs}$ tend to be older, more obese, and female. This would suggest that though CT scan is not the traditional diagnostic method for hiatal hernias, it is can still be used to find clinically significant cases. However, this visual marker does not correlate with increased COPD exacerbation in our study cohort.

Acute exacerbations of COPD account for millions of inpatient visits and billions of dollars in health care costs each year. ${ }^{10,22,23}$ These acute exacerbations are unequally distributed, with some patients exhibiting a frequent exacerbator phenotype, suffering from repetitive and severe exacerbations. ${ }^{24,25}$ These frequent exacerbators tend to have a greater impairment in health status, an elevated whiteblood cell count, and a history of GERD.

Presence of an $\mathrm{HH}$ is a structural risk factor for GERD that can be easily visualized on CT imaging. American and European studies report an incidence of $14 \%-24 \%,{ }^{26,27,28}$ higher than the $10 \%$ incidence found in our study population, which is likely related to patient selection and diagnostic method. While more women had $\mathrm{HHs}$ in our study, there is no clear gender association found in the literature. ${ }^{13}$ Traditionally, an $\mathrm{HH}$ is diagnosed with endoscopy or barium esophagram. ${ }^{29}$ However, it is commonly reported on CT scans of the thorax as an incidental finding. ${ }^{16}$ To our knowledge, there is no standard definition of size or parameters for measurement of $\mathrm{HH}$ on CT scans. In addition to answering the clinical question posed, we devised a systematic method for defining hiatal hernia on CT. Since COPD patients routinely undergo $C T$ scans of the thorax, our aim was to 1) formally define hiatal hernia seen on CT and 2) determine if these findings can be used as a visual marker to identify patients who may be frequent exacerbators, especially given the relationship between GERD and increased COPD exacerbations. We found no relationship between incidence of hiatal hernia and exacerbation rate.

Our understanding of the complex relationship between GERD and pulmonary disease is constantly evolving. Mechanisms involved are thought to include tracheal microaspiration of acid stimulating bronchospasm ${ }^{30}$ and increased airway hyper-reactivity associated with acid reflux into the lower esophagus. ${ }^{31,32}$ In our study, $19 \%$ of COPD individuals reported GERD symptoms as compared with $14 \%$ in unobstructed smokers, consistent with previously cited studies showing a higher incidence of GERD in COPD patients. As with other studies, we did find that GERD incidence 
increased with older age and obesity. ${ }^{33,34}$ To control for these risk factors, we used propensity scoring to create a control population that was matched for obesity and age among other factors and found no difference in exacerbation rates.

One interesting and unanticipated finding is the increased nebulizer and LABA/ICS use in unobstructed smokers with $\mathrm{HHs}$ that was independent of both dyspnea perception according to the $\mathrm{MMRC}$ and the presence of cough or phlegm, lending weight to the idea that acid reflux in the lower esophagus affects pulmonary function. Alternatively, this finding along with the increased rate of angina in the same group may be explained with symptom confusion on the part of the individuals, reflecting symptoms of acid reflux rather than true dyspnea or angina. The significantly increased rate of hyperlipidemia in the hernia group is most likely related to the increased incidence of obesity associated with HHs. Interestingly, other comorbidities such as hypertension and diabetes were not different between the 2 groups.

Weaknesses of our study include reliance on selfreported symptoms and diagnoses such as cough and acute exacerbations of COPD, the transient nature of $\mathrm{HHs}$ on imaging, and our relatively small sample size. Reports of acid reflux could not be confirmed with formal acid reflux questionnaires. However, the majority of validated GERD questionnaires use symptom-based questions similar to those in this study ${ }^{35}$ and guidelines by the American College of Gastroenterology ${ }^{36}$ support the clinical use of subjective symptoms and response to antacid therapy as a method of GERD diagnosis. Inconsistencies in self-reporting were observed with regards to exacerbation history, with some individuals reporting hospitalizations for shortness of breath in the previous year yet reporting having had no exacerbations. These individuals represented an extremely small minority, but highlight the drawbacks of subjective reporting. In addition, sliding hernias are by nature transient and our images only capture one moment in time. We chose to review inspiratory CT images to match the convention for CT thorax. However, very little is known regarding the behavior of $\mathrm{HHs}$ in relation to diaphragm movement during respiration. Further research comparing expiratory and inspiratory CT imaging for changes in the appearance of HHs would help clarify this question. Finally, there were fewer than anticipated HHs identified and as with any small sample size, there is an increased risk of type II error.

Strengths of the study include a large study population with extensively described symptom and medication history along with the availability of imaging for symptom correlation. We used a systematic method to standardize identification and characterization of $\mathrm{HH}$ s on HRCT imaging, adding weight to the use of this imaging modality as a diagnostic tool for HHs. In addition to examining the effect of respiration on $\mathrm{HH}$, future research in this unique cohort could also examine the effect of lung hyperinflation on HHs' size and motion. Finally, our imaging evaluation of $\mathrm{HH}$ focused on the presence and amount of gastric tissue that has herniated superiorly through the esophageal hiatus. It is possible that the size and integrity of the esophageal hiatus itself has more relevance to symptomatology, and therefore, serves as a better target for characterization with imaging.

In conclusion, the presence of an $\mathrm{HH}$ on an inspiratory HRCT scan did not predict increased symptoms or exacerbation rate in COPD individuals. Those with HHs were older, more obese, and more likely female compared to those without HHs. In addition, HRCTs of the chest may be used to identify and characterize $\mathrm{HHs}$ and may offer a convenient alternative diagnostic method.

\section{Acknowledgements}

The authors wish to thank the investigators of COPDGene for access to their considerable body of data and continued support of this research.

\section{Declaration of Interest}

None of the authors of this paper have any real or apparent conflicts of interest to disclose, nor have any financial or consulting relationships to report. The entire manuscript is the original work of the authors and there was no additional input from any agency or freelance writer. 


\section{References}

1. Kempainen RR, Savik K, Whelan TP, Dunitz JM, Herrington CS, Billings JL. High prevalence of proximal and distal gastroesophageal reflux disease in advanced COPD. Chest. 2007; 131(6): 1666-1671.

doi: http://dx.doi.org/10.1378/chest.06-2264

2. Casanova C, Baudet JS, del Valle Velasco M, et al. Increased gastro-oesophageal reflux disease in patients with severe COPD. Eur Respir J. 2004; 23(6): 841-845. doi: http://dx.doi.org/10.1183/09031936.04.00107004

3. Mokhlesi B, Morris AL, Huang C, Curcio AJ, Barrett TA, Kamp DW. Increased prevalence of gastroesophageal reflux symptoms in patients with COPD. Chest. 2001; 119: 1043-1048. doi: http://dx.doi.org/10.1378/chest.119.4.1043

4. Rascon-Aguilar IE, Pamer M, Wludyka $P$, et al. Role of gastroesophageal reflux symptoms in exacerbations of COPD. Chest. 2006; 130(4): 1096-1101. doi: http://dx.doi.org/10.1378/chest.130.4.1096

5. Martinez CH, Okajima Y, Murray S, et al. Impact of self-reported Gastroesophageal reflux disease in subjects from COPDGene cohort. Respir Res. 2014; 15: 62. doi: http://dx.doi.org/10.1186/1465-9921-15-62

6. Kim J, Lee JH, Kim Y, et al. Association between chronic obstructive pulmonary disease and gastroesophageal reflux disease: a national cross-sectional cohort study. BMC Pulm Med. 2013; 13: 1-10. doi: http://dx.doi.org/10.1186/1471-2466-13-51

7. Rogha M, Behravesh B, Pourmoghaddas Z, Najafabad I. Association of gastroesophageal reflux disease symptoms with exacerbations of chronic obstructive pulmonary. J Gastrointestin Liver Dis. 2010; 19(3): 253-256.

8. Rascon-Aguilar IE, Pamer M, Wludyka P, Cury J, Vega KJ. Poorly treated or unrecognized GERD reduces quality of life in patients with COPD. Dig Dis Sci. 2011; 56(7): 1976-1980.

doi: http://dx.doi.org/10.1007/s10620-010-1542-5

9. Strassels SA, Smith DH, Sullivan SD, Mahajan PS. The costs of treating COPD in the United States. Chest. 2001;119: 344-352. doi: http://dx.doi.org/10.1378/chest.119.2.344

10. Mannino DM, Buist AS. Global burden of COPD: risk factors, prevalence, and future trends. Lancet. 2007; 370(9589): 765-773. doi: http://dx.doi.org/10.1016/S0140-6736(07)61380-4

11. Chapman KR, Mannino DM, Soriano JB, et al. Epidemiology and costs of chronic obstructive pulmonary disease. Eur Respir J. 2006; 27(1): 188-207.

doi: http://dx.doi.org/10.1183/09031936.06.00024505

12. van Herwaarden MA, Samsom M, Smout AJ. The role of hiatus hernia in gastro-oesophageal reflux disease. Eur J Gastroenterol Hepatol. 2004; 16(9): 831-835. doi: http://dx.doi.org/10.1097/00042737-200409000-00003
13. Gordon C, Kang J, Neild P, Maxwell J. The role of the hiatus hernia in gastro-oesophageal reflux disease. Aliment Pharmacol Ther. 2004; 20 (7): 719-732. doi: http://dx.doi.org/10.1111/j.1365-2036.2004.02149.x

14. Kahrilas PJ. GERD pathogenesis, pathophysiology, and clinical manifestations. Cleve Clin J Med. 2003; 70: S4. doi: http://dx.doi.org/10.3949/ccjm.70.Suppl_5.S4

15. Abbara S, Kalan MM, Lewicki AM. Intrathoracic stomach revisited. AJR Am J Roentgenol. 2003; 181(2): 403-414. doi: http://dx.doi.org/10.2214/ajr.181.2.1810403

16. Pickhardt PJ, Boyce CJ, Kim DH, Hinshaw LJ, Taylor AJ, Winter TC. Should small sliding hiatal hernias be reported at CT colonography? Am J Roentgenol. 2011; 196(4): W400-W404. doi: http://dx.doi.org/10.2214/AJR.10.5392

17. Fukazawa K, Furuta K, Adachi K, et al. Continuous imaging of esophagogastric junction in patients with reflux esophagitis using 320-row area detector CT: A feasibility study. J Gastroenterol Hepatol. 2013; 28: 1600-1607.

18. Noth I, Zangan SM, Soares RV, et al. Prevalence of hiatal hernia by blinded multidetector CT in patients with idiopathic pulmonary fibrosis. Eur Respir J. 2012; 39: 344-351. doi: http://dx.doi.org/10.1183/09031936.00099910

19. American Thoracic Society(ATS). Recommended respiratory disease questionaires for use with adults and children in epidemiological research. ATS website. https://www.thoracic. org/statements/resources/archive/rrdquacer.pdf Accessed March 15, 2016.

20. Brant WE, Helms CA. Fundamentals of Diagnostic Radiology. Philadelphia, Pennsylvania: Lippincott Williams \& Wilkins; 2012.

21. Global initiative for chronic Obstructive Lung Disease (GOLD). Pocket guide to COPD diagnosis, management and prevention of COPD, 2010. GOLD website. http://www.goldcopd.org/ uploads/users/files/GOLD_Pocket_2010Mar31.pdf Published 2010. Accessed March 15, 2016.

22. Perera PN, Armstrong EP, Sherrill DL, Skrepnek GH. Acute exacerbations of COPD in the United States: inpatient burden and predictors of costs and mortality. COPD. 2012; 9(2): 131-141. doi: http://dx.doi.org/10.3109/15412555.2011.650239

23. Sharafkhaneh A, Petersen NJ, Yu HJ, Dalal AA, Johnson ML, Hanania NA. Burden of COPD in a government health care system: a retrospective observational study using data from the US Veterans Affairs population. Int J Chron Obstruct Pulmon Dis. 2010; 5:125-132.

24. Hurst JR, Vestbo J, Anzueto A, et al. Susceptibility to exacerbation in chronic obstructive pulmonary disease. $N$ Engl J Med. 2010; 363: 1128-1138.

doi: http://dx.doi.org/10.1056/NEJMoa0909883 
$\overline{\text { 25. Wedzicha JA, Brill SE, Allinson JP, Donaldson GC. Mechanisms }}$ and impact of the frequent exacerbator phenotype in chronic obstructive pulmonary disease. BMC Med. 2013; 11:181.

26. Wilson LJ, Ma W, Hirschowitz BI. Association of obesity with hiatal hernia and esophagitis. Am J Gastroenterol. 1999; 94: 28402844. doi: http://dx.doi.org/10.1111/j.1572-0241.1999.01426.x

27. Berstad A, Weberg R, Larsen IF, Hoel B, Hauer-Jensen M. Relationship of hiatus hernia to reflux oesophagitis a prospective study of coincidence, using endoscopy. Scand J Gastroenterol. 1986; 21: 55-58. doi: http://dx.doi.org/10.3109/00365528609034622

28. Avidan B, Sonnenberg A, Schnell TG, Chejfec G, Metz A, Sontag SJ. Hiatal hernia size, Barrett's length, and severity of acid reflux are all risk factors for esophageal adenocarcinoma. Am J Gastroenterol. 2002; 97: 1930-1936. doi: http://dx.doi.org/10.1111/j.1572-0241.2002.05902.x

29. Kahrilas PJ, Kim HC, Pandolfino JE. Approaches to the diagnosis and grading of hiatal hernia. Best Prac Res Clin Gastroenterol. 2008; 22(4): 601-616. doi: http://dx.doi.org/10.1016/j.bpg.2007.12.007

30. Jack CI, Calverley PM, Donnelly RJ, et al. Simultaneous tracheal and oesophageal $\mathrm{pH}$ measurements in asthmatic patients with gastro-oesophageal reflux. Thorax. 1995; 50: 201-204. doi: http://dx.doi.org/10.1136/thx.50.2.201

31. Wu D, Tanifuji Y, Kobayashi H, Yamauchi K, Kato C, Suzuki $\mathrm{K}$, Inoue $\mathrm{H}$. Effects of esophageal acid perfusion on airway hyperresponsiveness in patients with bronchial asthma. Chest. 2000; 118(6): 1553-1556.

doi: http://dx.doi.org/10.1378/chest.118.6.1553

32. Vincent D, Cohen-Jonathan AM, Leport J, et al. Gastrooesophageal reflux prevalence and relationship with bronchial reactivity in asthma. Eur Respir J. 1997; 10(10): 2255-2259.

doi: http://dx.doi.org/10.1183/09031936.97.10102255

33. Hampel H, Abraham NS, El-Serag HB. Meta-analysis: obesity and the risk for gastroesophageal reflux disease and its complications. Ann Intern Med. 2005; 143(3): 199-211. doi: http://dx.doi.org/10.7326/0003-4819-143-3-200508020-00006

34. Johnson DA, Fennerty MB. Heartburn severity underestimates erosive esophagitis severity in elderly patients with gastroesophageal reflux disease. Gastroenterology. 2004; 126(3): 660-664.

doi: http://dx.doi.org/10.1053/j.gastro.2003.12.001
35. Stanghellini V, Armstrong D, Mönnikes H, Bardhan K. Do we need a new gastro-oesophageal reflux disease questionnaire? Aliment Pharmacol Ther. 2004; 19(5): 463-479. doi: http://dx.doi.org/10.1046/j.1365-2036.2004.01861.x

36. DeVault KR, Castell DO. Updated guidelines for the diagnosis and treatment of gastroesophageal reflux disease. Am J Gastroenterol. 2005; 100: 190-200. doi: http://dx.doi.org/10.1111/j.1572-0241.2005.41217.x 